\title{
INFLUENCE OF HARVESTING DATE ON CHEMICAL MATURITY FOR PROCESSING QUALITY OF POTATOES
}

\author{
M. Sharkar ${ }^{1}$, J. U. Ahmed ${ }^{1}$, M. A. Hoque ${ }^{2}$ and M. Mohi-Ud-Din ${ }^{1 *}$
}

\begin{abstract}
The present study was conducted to find out a suitable harvesting date of processing potato varieties (Asterix, Courage and Lady Rosetta) from three different harvest dates [80, 90, and 100 days after planting (DAP) harvest] by chemical maturity monitoring. Eighty DAP harvest resulted the lowest mean total soluble sugar (TSS) (3.77 mg/g FW), reducing sugar (RS) $(1.57 \mathrm{mg} / \mathrm{g} \mathrm{FW})$, sucrose $\left(2.40 \mathrm{mg} \mathrm{g}^{-1} \mathrm{FW}\right)$, fructose $(0.77 \mathrm{mg} / \mathrm{g}$ FW) and polyphenol $(238.94 \mu \mathrm{g} / \mathrm{g} \mathrm{FW})$ contents in all the varieties and at the same DAP harvest, dry matter (DM) content (21.71\%) and chip color index (CCI) (0.67) remained at the lowest. Tubers harvested at $80 \mathrm{DAP}$ produced good quality and acceptable colored processed products as it meets up the required processing quality, but lesser DM content might increase the cost of the product. Optimum DM content $(24.07 \%)$ with moderate level of different sugar contents and acceptable CCI $(1.13$ to $1.85,<2.00)$ was found at 90 DAP harvest. Therefore, 90 DAP harvest could be considered as suitable harvesting date for processing by compromising some quality parameters (TSS, RS, sucrose, fructose and polyphenol contents). Among the varieties, Lady Rosetta and Courage were preferable for producing quality potato products. Highly significant and positive correlation existed between CCI and different chemical parameters. A strong correlation coefficient $\left(\mathrm{r}=0.822^{* *}\right)$ and good fit $\left(\mathrm{R}^{2}=0.6755\right)$ of the regression equation $(\mathrm{CCI}=$ $0.9341 \mathrm{RS}-0.4969$ ) between CCI and RS indicated that RS content played the vital role in the browning of the processed potato products.
\end{abstract}

Keywords: Reducing sugar, sucrose, chip color index, processing potatoes.

\section{Introduction}

Potato (Solanum tuberosum L.) is one of the most important vegetable crops and it is a part of daily food utilization of almost all the world population (Mathur, 2003). It is a staple diet in European countries and its utilization both as processed and fresh forms are increasing considerably in Asian countries (Brown, 2005). It is consumed in different forms like boiled or fried and many different processed products like chips,
French fries, powder, potato papad etc. which are enjoyed across the generations and continents. Processing quality of potato tubers is determined by high dry matter and low reducing sugar and phenol contents (Kadam et al., 1991). High dry matter content increases chip yield, crispy-consistency and reduces oil absorption during cooking (Pedreschi et al., 2005; Rommens et al., 2010) and high polyphenols are responsible for an enzymatic darkening of potato products (Wang-Pruski

\footnotetext{
${ }^{1}$ Department of Crop Botany, Bangabandhu Sheikh Mujibur Rahman Agricultural University, Gazipur 1706, ${ }^{2}$ Department of Horticulture, Bangabandhu Sheikh Mujibur Rahman Agricultural University, Gazipur 1706, Bangladesh. *Corresponding author: mmu074@bsmrau.edu.bd
} 
and Nowak, 2004). Low reducing sugars and phenol contents are required to avoid dark color and bitter taste of processed products, which negatively affect consumer acceptance (Wang-Pruski and Nowak, 2004). For making good quality French fry, the reducing sugar content of potatoes is required to be low (Marquez and Anon, 1986). The principal reason for the critical role of hexose reducing sugars in potato quality is the fact that frying at high temperature results in a typical Maillard reaction between these sugars and the amino acid groups of nitrogenous compounds, resulting in a dark colored, bitter testing product (Shallenberger et al., 1959).

Sugar contents in potato are complex, and the concentration levels vary according to the maturity of the harvested crop as well as the environment where the crop is grown. Apart from cultivar differences, maturity may be one of the principal factors affecting sugar content in potato tuber (Burton and Wilson, 1978). There is considerable variation among cultivars with regards to their susceptibility to the degree of maturation and related to physiological process (Es and Hartmans, 1987). However, tuber may be physically mature without being chemical maturation (low sugar concentration). Optimal processing quality for potato tuber is defined currently in terms of a chemical maturity when sucrose and glucose contents are minimal (Sowokinos and Preston, 1988). The levels of sugar in processing potato should be $1.5 \mathrm{mg} / \mathrm{g}$ fresh weight or less at harvest to minimize accumulation of reducing sugars.

Chemical Maturity Monitoring (CMM) involves analysis of tuber sugar contents, is a highly useful approach for tuber management during pre- and post-harvest periods (Sowokinos and Preston, 1988). Processing quality during storage is adversely affected by field treatments that enhanced tuber maturity at harvest. By minimizing the harvest of immature or stressed tubers and carefully assessing their progress in storage, product quality in chips and French fries can be controlled with minimal loss of raw source material (Mazza, 1983). CMM is one of the commercially feasible methods to rapidly measure the chemical maturity of potatoes from the field up to the time of processing on the basis of sugar content. Potatoes reach chemical maturity during a normal growth process when free sugars drop to minimum level for processing (Preston, 2003). Monitoring the chemical maturity of potatoes during development, at harvest, and in storage can help to minimize losses from immaturity and/or stress effects that influence processing product color i.e. chips and fries (Preston, 2003).

Different research institutions in Bangladesh prescribed the suitable harvesting dates of their developed processing potato varieties. However, the indication is based on yield and physical maturity, although chemical maturity is more precise indication used to determine the quality of processing potato varieties. Evidently, the chemical maturity is considered to be the key factor that affects the processing quality of potato. The approach of this study is to check the effect of harvesting dates on the chemical maturity and polyphenol contents of potato tubers; and to determine their relationship with chip color of the processing varieties cultivated in Bangladesh. 
Materials and Methods

\section{Location, plant materials and experimental design}

The experiment was conducted at the research farm of Bangabandhu Sheikh Mujibur Rahman Agricultural University (BSMRAU), Gazipur, Bangladesh. Three processing potato varieties (viz. Asterix, Courage and Lady Rosetta) cultivated in Bangladesh were collected from the Tuber Crops Research Center (TCRC) of the Bangladesh Agricultural Research Institute (BARI) and Bangladesh Agricultural Development Corporation (BADC). The experiment was laid out in a 2-factored Randomized Complete Block Design with 4 replications. Three processing potato varieties represented Factor $\mathrm{A}$ and harvesting dates of 80, 90, and 100 days after planting (DAP) represented Factor B.

\section{Land preparation, fertilizer application and tuber planting}

The experimental field was mechanically ploughed, laddered and leveled until fine tilth. Irrigation channels were prepared around the plots as per design. A fertilizer dose of $\mathrm{N}, \mathrm{P}, \mathrm{K}$ and $\mathrm{S}$ were applied as per fertilizer recommendation guide in the form of Urea, Triple Super Phosphate (TSP), Muriate of Potash (MP), Gypsum, respectively along with cow dung. Full doses of cow dung (10 t/ha), TSP (150 kg/ha), MP (250 kg/ ha), Gypsum (120 kg/ha), and half doses of Urea $(125 \mathrm{~kg} / \mathrm{ha})$ were applied at the final land preparation. The rest half doses of Urea (125 kg/ha) were applied as top dressings at 30 DAP followed by earthing up and light irrigation. Fertilizers were placed in row which was deeper than the tuber row. Unit plot size was $4 \mathrm{~m} \times 3 \mathrm{~m}$ and the tubers were planted following $60 \mathrm{~cm} \times 25 \mathrm{~cm}$ spacing. Sixteen seed tubers were placed in every row.

\section{Intercultural operations and tuber harvesting}

Intercultural operations such as weeding, irrigation, earthing up etc. were done manually. First earthing up was done at 30 DAP when the plant attained a height of about $15-20 \mathrm{~cm}$ while the last one was done after 20 days of first earthing up. First irrigation was applied just after planting while the rest irrigations were done at 20,30, 40, and 50 days after planting. Ridomil Gold was sprayed at the rate of $5 \mathrm{~g} / \mathrm{L}$ once to prevent the late blight disease of potato. Hand picking was done to prevent the cutworm attack. The haulms were cut at 70, 80, and 90 DAP. Tubers were harvested 10 days after haulm cutting. After harvesting potato tubers were classified into four grades according to Karim et al. (2010), estimating diameter at the middle of the potato tubers. These grades were under grade $(<28 \mathrm{~mm})$, grade A (28-40mm), Grade B (41-55 mm) and over grade $(>55 \mathrm{~mm})$. Among these grades, grade A and grade B together were considered as processable grade tuber.

\section{Determination of tuber dry matter content}

Five processable grade tubers were chopped in thin pieces and about $50 \mathrm{~g}$ fresh sample were oven dried at $80^{\circ} \mathrm{C}$ till constant weight was achieved. Then the moisture percentage was determined and this was deducted from the total $100 \%$ moisture to get the dry matter (\%). 
Extraction and determination of soluble sugars

Sugar content of potato was extracted by following the procedure of Xue (1985) with slight modification. Briefly, $500 \mathrm{mg}$ of fresh potato flesh was extracted thrice with $5 \mathrm{ml}$ of $80 \%(\mathrm{v} / \mathrm{v})$ ethanol at $80^{\circ} \mathrm{C}$ for $30 \mathrm{~min}$ and the extracts were centrifuged at $5000 \mathrm{rpm}$ for 10 min. The supernatants were combined in a 50 $\mathrm{ml}$ beaker and placed in a water bath at 80 $85^{\circ} \mathrm{C}$ until the volume is reduced to about 1 $\mathrm{ml}$. The sugar extract was transferred to a 10 $\mathrm{ml}$ volumetric flask by 3-4 wash with distilled water and used for assaying total soluble sugars, reducing sugar, sucrose, glucose and fructose contents.

Glucose content: Glucose content was estimated by glucose enzymatic assay kit (Linear Chemical, Spain) following the procedure attached with the kit pack. Briefly, $500 \mu \mathrm{l}$ of sugar extract was taken in a test tube and $5 \mathrm{ml}$ of enzyme reagent was added to convert glucose to a colored product. Then the tubes were kept for $10 \mathrm{~min}$ in room temperature and the absorbance reading was taken at $500 \mathrm{~nm}$. A standard curve was made from a series of standard solution of glucose and the amount of glucose was estimated using the standard curve.

Fructose content: Fructose content of potato flesh was measured by the anthrone colorimetric method following the procedure of Kang et al. (2009). Briefly, $1 \mathrm{ml}$ of sugar extract was taken in a test tube and $5 \mathrm{ml}$ of anthrone reagent (conc. $\mathrm{H}_{2} \mathrm{SO}_{4}$ : anthrone powder $=1$ Lit: $2 \mathrm{gm}$ ) was mixed in it and was incubated at $40^{\circ} \mathrm{C}$ for $10 \mathrm{~min}$. Then it was allowed to cool down and absorbance was read at $510 \mathrm{~nm}$. A standard curve was prepared from a series of standard solution of fructose and the amount of fructose was estimated using the standard curve.

Reducing sugar content: Reducing sugar content was measured by DNS colorimetric method following the procedure of Miller (1959) with some modifications. Initially, $3 \mathrm{ml}$ of the sugar extract was taken in the test tube and $3 \mathrm{ml}$ of DNS reagent was added. The content was heated in a boiling water bath for $5 \mathrm{~min}$ and then $1 \mathrm{ml}$ of $40 \%$ Rochelle salt solution was mixed when the contents of the tubes were still warm. Then the mixture was kept for cooling and the intensity of dark red color was taken at 510 nm. A series of standards were prepared using glucose. Then the amount of reducing sugar present in the samples were calculated using the standard curve.

Sucrose content: Sucrose content was measured through the procedure of Kang et al. (2009). Initially, $0.75 \mathrm{ml}$ of extract was taken in a test tube and $0.25 \mathrm{ml}$ of $2 \mathrm{M} \mathrm{KOH}$ was mixed and boiled for $10 \mathrm{~min}$. Then it was allowed to cool down at room temperature and $5 \mathrm{ml}$ anthrone reagent was added to the mixture and incubated at $40^{\circ} \mathrm{C}$ for $15 \mathrm{~min}$. The absorbance was taken at $510 \mathrm{~nm}$ after cooling the mixture. A series of standard solution of sucrose were prepared to make a standard curve to calculate the amount of sucrose present in the sample.

Total soluble sugar content: Total soluble sugar was calculated by the summation of glucose, fructose and sucrose contents as done following the procedure described by AduKwarteng et al. (2014). 


\section{Extraction and determination of total polyphenol content}

The extraction was done by following the procedure of Nayak et al. (2011). In short, $1 \mathrm{~g}$ of potato flesh was peeled, chopped and homogenized with $10 \mathrm{ml}$ of HPLC grade methanol to a uniform consistency by mortar and pestle. The samples were centrifuged at $15,000 \mathrm{~g}$ at $4^{\circ} \mathrm{C}$ for $20 \mathrm{~min}$ and the supernatants were stored at $-20^{\circ} \mathrm{C}$ for further analysis. Total polyphenol content was determined spectrophotometrically according to the FolinCiocalteu method (Singleton et al., 1999, Ainsworth and Gillespie, 2007) with slight modification. The absorbance of the reaction solutions was measured at $765 \mathrm{~nm}$ against a blank. The measurements were compared to a standard curve of gallic acid solutions and expressed as $\mu \mathrm{g}$ of gallic acid equivalents per $\mathrm{g}$ fresh weight \pm standard error $(\mu \mathrm{g}$ GAE/g $\mathrm{FW}) \pm \mathrm{SE}$.

\section{Potato chips production and determination of chips color index}

Potato chips from processable grade were produced according to Kita et al. (2014) with slight modification. After washing potatoes were cut into slices of $2 \pm 0.1 \mathrm{~mm}$ thickness with a potato slicer, washed in cold saline water $(\mathrm{NaCl} @$ of $20 \mathrm{~g} / \mathrm{L}$ ) and superficially dried by paper towels. The chips were deep fried about $3 \mathrm{~min}$ in refined rice bran oil heated to $180^{\circ} \mathrm{C}$. After discharging of the oil and cooling, chips were packed in aluminum foil packages and taken for further use.

Chips Color Index was determined by using "USDA Color Standards for Frozen French Fried Potatoes" according to Pedreschi et al. (2012) with some modifications. Each sample consisted of 10 chips were underwent to 10 assessors for sensory assessment. Each assessor compared each sample chip with the pictures shown in the standard color chart presented in the "USDA Color Standards for Frozen French Fried Potatoes" and a code was assigned based on the color tone of the analyzed sample. The color assessment was done under an open light condition similar to a day light overcast sky. The chart was designed to evaluate the color of French fries, but it has been used successfully as well to evaluate the color of potato chips (Pedreschi et al., 2005).

\section{Statistical analysis}

Statistical analysis was performed using Statistix 10 software. Data were subjected to two-way analysis of variance (ANOVA) for mean comparison, and significant differences were calculated according to Duncan's multiple range test (DMRT). Data were reported as mean \pm standard error (SE). Differences at $\mathrm{p}<0.05$ were considered to be statistically significant. Correlation analysis was performed by Minitab 16 software.

\section{Results and Discussion}

The ANOVA for processing qualities revealed that the main effects of the varieties and harvest dates were significant for all the quality parameters (Table 1). Two-way interaction between the varieties and harvest dates were significant apart from reducing sugar and chip color index.

\section{Dry matter content}

Dry matter (DM) content was increased up to 90 DAP harvest and thereafter decreased in all three potato varieties (Fig. 1a). The 
Table 1. Mean squares of variance and their effect on processing quality of potato tubers

\begin{tabular}{lccccccccc}
\hline $\begin{array}{l}\text { Source of } \\
\text { variation }\end{array}$ & \multirow{2}{*}{ DF } & \multicolumn{7}{c}{ Mean Squares } \\
\cline { 3 - 9 } Variety (V) & 2 & $72.27^{* *}$ & $177.96^{* *}$ & $0.51^{* *}$ & $0.77^{* *}$ & $2.57^{* *}$ & $138.90^{* *}$ & $22193.40^{* *}$ & $2.03^{* *}$ \\
Harvest date & 2 & $18.28^{* *}$ & $33.56^{* *}$ & $0.91^{* *}$ & $0.09^{*}$ & $2.01^{* *}$ & $35.42^{* *}$ & $15074.80^{* *}$ & $4.93^{* *}$ \\
(HD) & 4 & $5.26^{*}$ & $24.29^{* *}$ & $0.10^{* *}$ & $0.15^{* *}$ & 0.11 & $27.12^{* *}$ & $3341.50^{* *}$ & 0.03 \\
V $\times$ HD & 24 & 1.92 & 0.22 & 0.01 & 0.02 & 0.06 & 0.21 & 228.40 & 0.03 \\
Error & 24 &
\end{tabular}

*indicates significant at $p \leq 0.05 ; * *$ indicates significant at $p \leq 0.01$. Here, $\mathrm{DF}=$ degrees of freedom, DM= dry matter, $\mathrm{TSS}=$ total soluble sugars, $\mathrm{RS}=$ reducing sugars, $\mathrm{CCI}=$ chip color index.

increment was significant in variety Lady Rosetta and Asterix but in case of courage it was non-significant; and the decrease in DM content after 90 DAP harvest was significant only in Asterix. In all 3 varieties, the highest DM content was attained at 90 DAP harvest compared to 80 and 100 DAP.

In case of harvest dates, 90 DAP harvest (24.07\%) yielded significantly higher DM than 80 DAP (21.71\%) and $100 \operatorname{DAP}(22.27 \%)$ DAP harvest. A slight decrease in dry matter accumulation at later stage of maturity was also observed earlier (Söğüt and Öztürk, 2011) that resembles the present findings. This reduction in dry matter accumulation at the late harvest was due to the imbalance between maintenance respiration and slow growth of the tubers at high soil temperatures (Söğüt and Öztürk, 2011).

Mean DM content of the varieties showed statistically significant difference among them. Lady Rosetta had significantly higher DM content (24.87\%) as compared to Asterix (20.02\%) and Courage (23.14\%). The result indicated that variety Lady Rosetta could be preferred as suitable variety and 90 DAP harvest could be optimum to get higher DM content. Sharkar et al. (2019) also suggested that 90 DAP harvest was suitable for processing considering optimum dry matter content, specific gravity, starch content, processable tuber yield and total tuber yield in the similar growing conditions.

Dry matter is an index of better processing quality, as it results in lesser oil absorption and less frying time (Pavlista and Ojala, 1997). Particularly with crisps, lower dry matter contents require more energy to drive out the moisture and more oil to replace it (Lulai and Orr, 1979). If too much oil is required, i.e. dry matters are low; the resulting crisps are soggy and oily with a reduced shelf-life and increased production costs. Higher dry matter results in better textured products, crisps are crunchier and french fries are mealier and firmer (Genet, 1992).

\section{Total soluble sugar content}

Total soluble sugar (TSS) was found to be increased with crop maturity in all the three varieties, but the increment was significant only in Asterix (Fig. 1b). In all 3 varieties, the lowest TSS was attained at 80 DAP harvest.

In case of harvest dates, 80 DAP harvest (3.77 $\mathrm{mg} / \mathrm{g}$ ) gave significantly the lowest TSS than 90 DAP $(4.70 \mathrm{mg} / \mathrm{g})$ and 100 DAP (7.01 mg/g) harvest. Taking varietals means of TSS, variety Lady Rosetta had significantly the lowest TSS (2.67 mg/g FW) as compared 

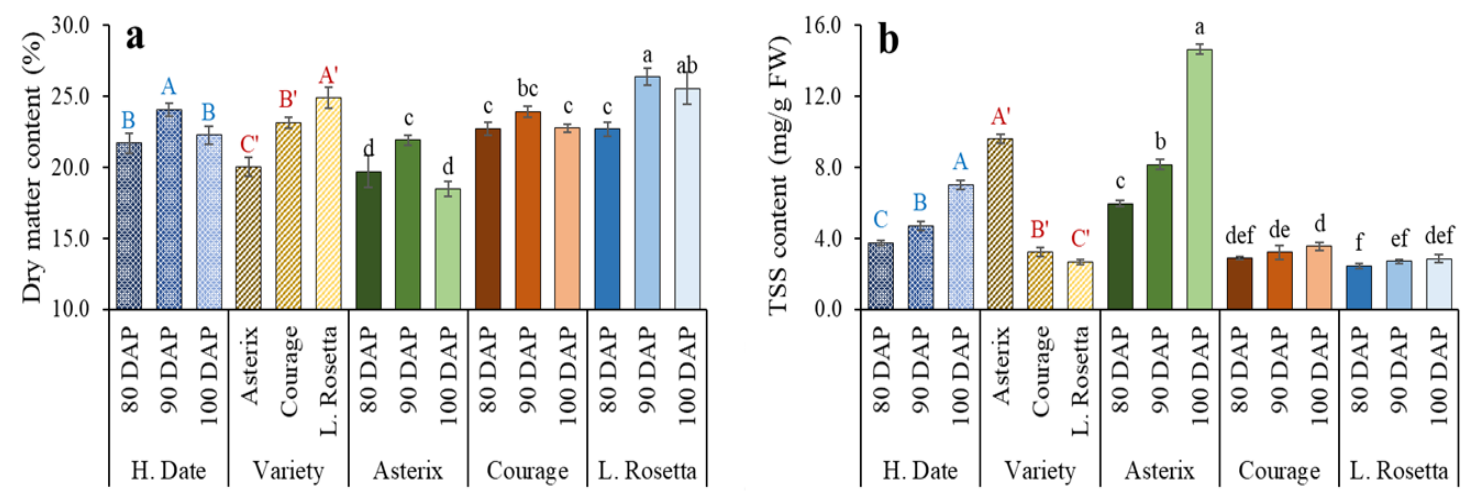

Fig. 1. Effect of harvest date, variety and their interaction on the (a) dry matter content and (b) total soluble sugar content of potatoes. Mean $( \pm \mathrm{SE})$ was calculated from four replicates. Vertical bars represent $\pm \mathrm{SE}$ value for the mean. Different uppercase letters, prime-marked uppercase letters and lowercase letters on the columns are significantly different within the groups at $p \leq 0.05$ by DMRT.

to Courage $(3.22 \mathrm{mg} / \mathrm{g} \mathrm{FW})$ and Asterix (9.60 $\mathrm{mg} / \mathrm{g} \mathrm{FW).} \mathrm{The} \mathrm{result} \mathrm{revealed} \mathrm{that} 80$ DAP harvest may be suitable harvesting time to get lower level of TSS and variety Lady Rosetta can be preferred for processing potato products.

Lower TSS in potatoes can be desirable because lower TSS apparently indicate lower reducing sugar and sucrose content in these potatoes varieties.

\section{Glucose and fructose contents}

In all varieties, there were significant decline in glucose content with the increasing harvest dates (Fig. 2a). Hundred DAP harvest had the lowest glucose content (0.07 mg/g FW) compared to 80 DAP (0.60 $\mathrm{mg} / \mathrm{g} \mathrm{FW})$ and $90 \mathrm{DAP}(0.45 \mathrm{mg} / \mathrm{g} \mathrm{FW})$ harvest. Among the varieties, significantly the lowest mean glucose content was achieved in Courage $(0.25 \mathrm{mg} / \mathrm{g} \mathrm{FW})$ and Lady Rosetta $(0.25 \mathrm{mg} / \mathrm{g}$ FW) compared with Asterix (0.61 mg/g FW).
Fructose content was increased with crop maturity in all varieties, but the increment was significant in Asterix (Fig. 2b). At all harvesting dates, Asterix contained significantly higher amount of fructose than Courage and Lady Rosetta.

From the harvest dates, it was found that 100 DAP harvest yielded significantly higher fructose content $(1.08 \mathrm{mg} / \mathrm{g} \mathrm{FW})$ than that of 80 DAP $(0.77 \mathrm{mg} / \mathrm{g} \mathrm{FW})$ and 90 DAP $(0.90$ $\mathrm{mg} / \mathrm{g}$ FW) harvest. Among the varieties, significantly the highest mean fructose content was achieved in Asterix $(1.19 \mathrm{mg} / \mathrm{g}$ FW) compared with Courage $(0.87 \mathrm{mg} / \mathrm{g}$ FW) and Lady Rosetta $(0.69 \mathrm{mg} / \mathrm{g} \mathrm{FW})$.

In the present study, the declining tendency in the glucose content with crop maturity apparently due to the rapid conversion of glucose molecule to starch. Increasing fructose content with the crop maturity might be due to the accumulation of unused fructose molecules in the potato tissue and comparatively slower conversion of fructose molecules to starch. 


\section{Total reducing sugar content}

The reducing sugar (RS) content markedly increased with increasing the harvest dates in all potato varieties (Fig. 2c). Lowest RS contents were found at 80 DAP harvest in all three varieties. Variety Asterix resulted in comparatively higher RS content than that of Lady Rosetta at all harvest dates.

In case of harvest dates, 80 DAP $(1.57 \mathrm{mg} / \mathrm{g}$ FW) harvest gave significantly the lowest mean RS content than 90 DAP (1.94 mg/g FW) and 100 DAP (2.39 mg/g FW) harvest. Taking the varietal means, variety Courage $(1.70 \mathrm{mg} / \mathrm{g}$ FW) and Lady Rosetta $(1.70 \mathrm{mg} / \mathrm{g}$ FW) had significantly lower mean RS content than that of Asterix (2.5 mg/g FW). That is, variety Asterix yielded 1.4 times higher RS content than that of Courage and Lady Rosetta.

The result also indicated that 80 DAP harvest could be most suitable harvest date to obtain the lowest reducing sugar content and variety Courage and Lady Rosetta were comparatively preferable than Asterix. Because, Marwaha (1998) suggested that, minimum reducing sugar content should be taken as the basis for chemical maturity of potatoes under short day conditions. Low reducing sugar and phenol contents are required to avoid dark color and bitter taste of processed products, which negatively affect consumer acceptance (Wang-Pruski and Nowak, 2004). Lisinska and Leszczynski (1989) reported that a low reducing sugar content is required $(<2.5-3$ $\mathrm{mg}$ of reducing sugar per gram of potato) to minimize color development during frying of potato chips, which is generated by the non-enzymatic Maillard browning reaction. The upper acceptable limit of reducing sugar content is $150 \mathrm{mg} / 100 \mathrm{~g}$ fresh weight (Pandey et al., 2005). For making good quality French fry, the content of reducing sugars in potatoes is required to be low (Marquez and Anon, 1986). Because the presence of high levels of reducing sugars not only causes browning, but also generates acrylic amide by the Maillard reaction which is a highly undesirable attribute for consumers (Chen et. al., 2010).

\section{Sucrose content}

Sucrose content was increased with the crop maturity in all varieties, but the increment was significant only in Asterix (Fig. 2d). Variety Asterix resulted in significantly higher sucrose content at all harvest dates in comparison with those of Courage and Lady Rosetta.

Regarding the harvest dates, 80 DAP (2.40 $\mathrm{mg} / \mathrm{g} \mathrm{FW}$ ) harvest gave significantly the lowest mean sucrose content than 90 DAP $(3.36 \mathrm{mg} / \mathrm{g}$ FW) and 100 DAP (5.87 mg/g FW) harvest. Hundred DAP harvest resulted in significantly the highest mean sucrose content $(5.87 \mathrm{mg} / \mathrm{g}$ FW) which was about 2-fold higher than those of 80 and 90 DAP harvest. Considering the varieties, the lowest mean sucrose content was found in Lady Rosetta. Variety Asterix (7.80 $\mathrm{mg} / \mathrm{g}$ FW) yielded the highest mean sucrose content which was 4-fold higher than that of Courage $(2.10 \mathrm{mg} / \mathrm{g} \mathrm{FW})$ and Lady Rosetta (1.73 mg/g FW).

The amount of sucrose found in potatoes at harvest is influenced by many factors. These factors may include variety, planting date, growing location, soil fertility, water availability, and any stress-inducing event. The results of the present study indicated that 80 DAP harvest could be better to maintain the low sucrose level. Although sucrose does not participate in non-enzymatic browning 

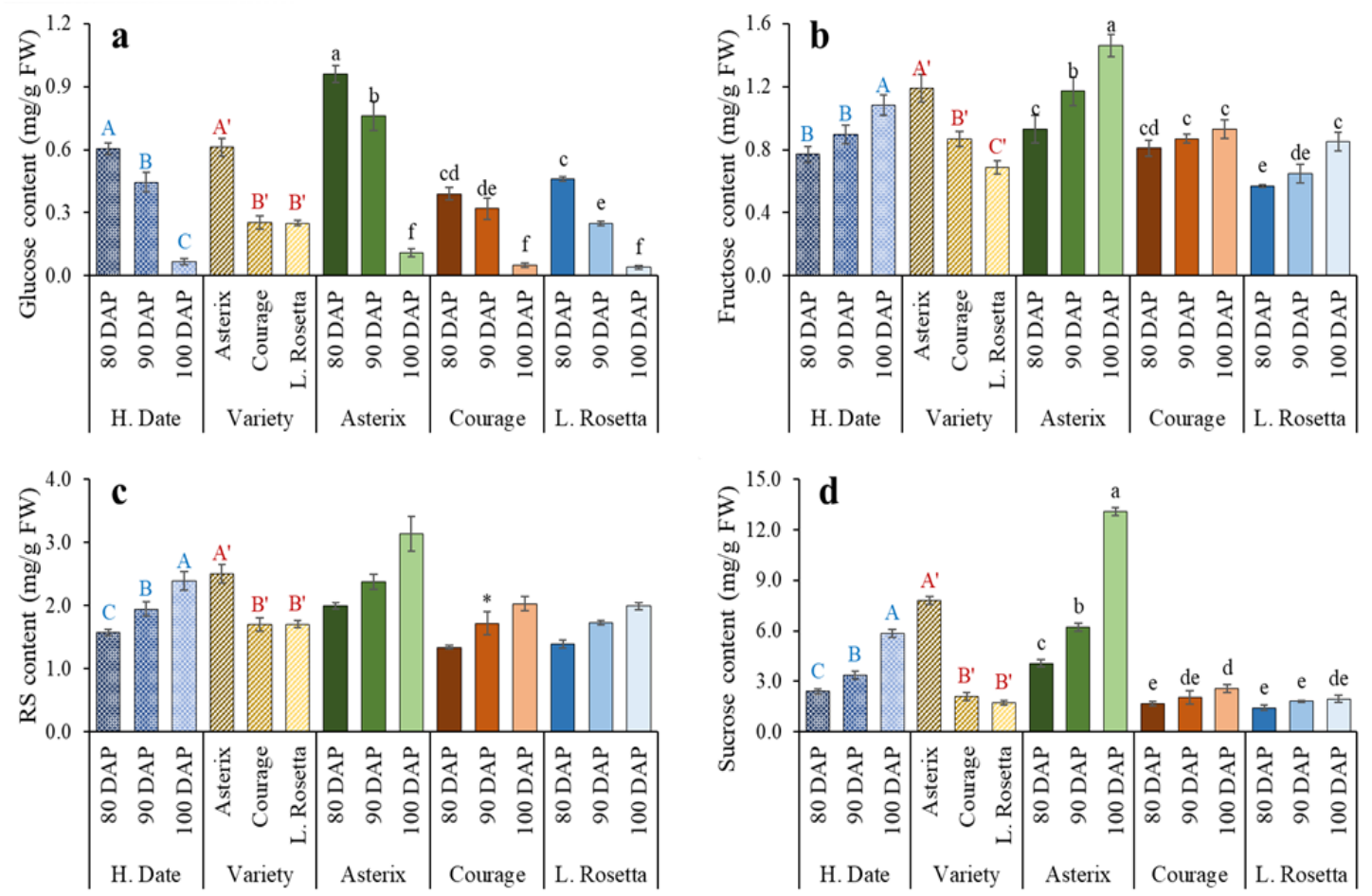

Fig. 2. Effect of harvest date, variety and their interaction on the, (a) glucose content, (b) fructose content, (c) reducing sugar content and (d) sucrose content of potatoes. Mean $( \pm S E)$ was calculated from four replicates. Vertical bars represent $\pm \mathrm{SE}$ value for the mean. Different uppercase letters, prime-marked uppercase letters and lowercase letters on the columns are significantly different within the groups at $p \leq 0.05$ by DMRT. *indicates the interaction effect is not significant by ANOVA.

of processed product directly, it serves as a substrate for reducing sugar production via the storage activated enzyme invertase (Pressey, 1969). So the level of sucrose in processing potato tubers should be $1.5 \mathrm{mg} / \mathrm{g}$ or less at harvest to minimize accumulation of reducing sugar over long-term storage (Burton, 1966; Sowokinos and Preston, 1988).

\section{Total polyphenol content}

Total polyphenol content increased with increasing the harvest dates and the increment was significant up to 90 DAP harvest in all varieties (Fig. 3a). The lowest polyphenol content was found at 80 DAP harvest in all three varieties.

In case of harvest dates, 80 DAP harvest (238.94 $\mu \mathrm{g} / \mathrm{g} \mathrm{FW}$ ) gave significantly lower mean polyphenol content followed by 90 DAP (296.99 $\mu \mathrm{g} / \mathrm{g} \mathrm{FW})$ and 100 DAP (303.67 $\mu \mathrm{g} / \mathrm{g} F W)$ harvest. Among the varieties, significantly lower mean polyphenol content was estimated in Lady Rosetta $(233.66 \mu \mathrm{g} / \mathrm{g}$ FW) compared with Courage $(287.21 \mu \mathrm{g} / \mathrm{g}$ FW) and Aserix (318.73 $\mu \mathrm{g} / \mathrm{g} \mathrm{FW})$.

The results of the study showed that Lady Rosetta gave the lowest mean polyphenol 
content at 80 DAP harvest which is required for good colored and quality processed product. Higher polyphenol contents are responsible for an enzymatic darkening (Wang-Pruski and Nowak, 2004). It was reported that minimum polyphenol content is taken as the basis for chemical maturity of potatoes for processing because low reducing sugar and polyphenol contents are required to avoid dark color and bitter taste of processed products, which negatively affect consumer acceptance (Wang-Pruski and Nowak, 2004).

\section{Chip color index}

The Chip color index (CCI) was found to be increased with crop maturity and the increment was significant for all the 3 varieties up to 100 DAP harvest (Fig. 3b). The lowest CCI was found at 80 DAP harvest in all the three varieties. Variety Courage yielded markedly lower CCI than those of Lady Rosetta and Asterix at all dates to harvest.

Considering the harvest dates, significantly lower CCI was achieved in 80 DAP harvest
(0.67) followed by 90 DAP (1.42) and 100 (1.94) DAP harvest. Among varieties, lower mean CCI was obtained in Courage (1.09) followed by Lady Rosetta (1.12) and Asterix (1.82).

The result revealed that 80 DAP harvest is most suitable if CCI score of 2.0 is taken as upper limit of acceptability (Pedreschi et al., 2012). Processing varieties Courage and Lady Rosetta yielded desirable CCI at all 3 DAP harvests. The chips produced from Asterix were caramelized at all dates of harvest and degree of caramelization increased at later harvest dates due to higher contents of sugar and polyphenol than Courage and Lady Rosetta (Plate 1). More recent studies refute the opinion that potato chip color is a result of a caramelization of sugars (Gould, 1988) and production of acrylamide (Mottram et al., 2002) as a result of the browning reaction, also known as Maillard reaction. A nonenzymatic browning develops during the frying process, which has been attributed to a reaction among reducing sugars (glucose and
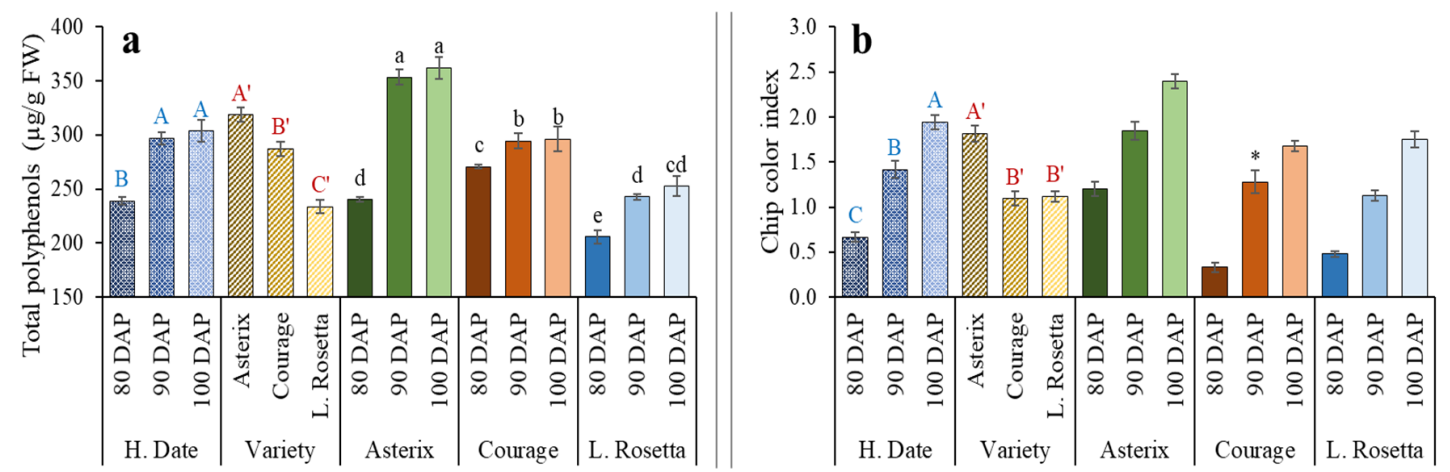

Fig. 3. Effect of harvest date, variety and their interaction on the (a) total polyphenol content and (b) chip color index of potatoes. Mean $( \pm \mathrm{SE})$ was calculated from four replicates. Vertical bars represent $\pm \mathrm{SE}$ value for the mean. Different uppercase letters, prime-marked uppercase letters and lowercase letters on the columns are significantly different within the groups at $p \leq 0.05$ by DMRT. *indicates the interaction effect is not significant by ANOVA. 

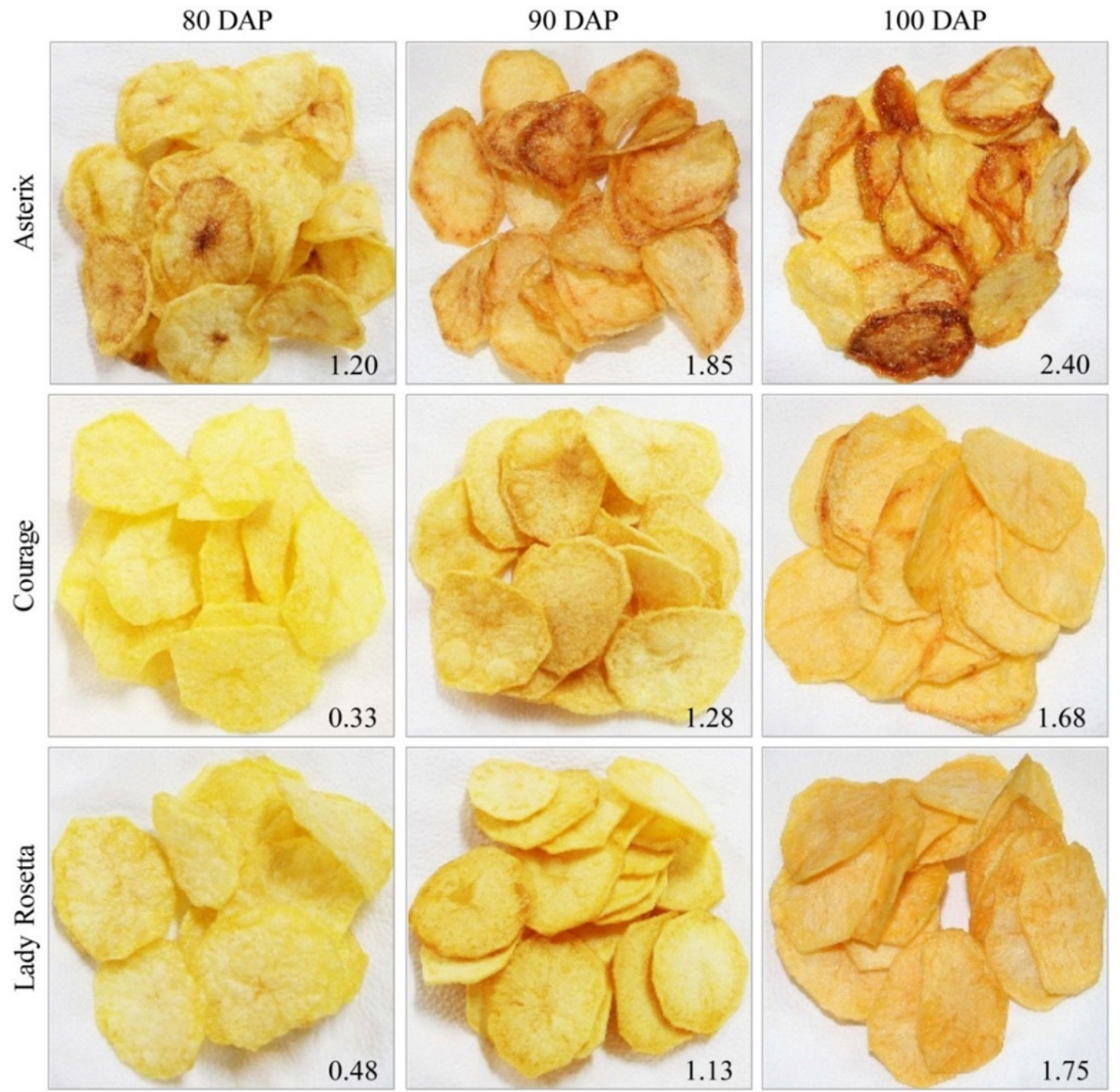

Plate 1. Color of chips produced from the potato varieties harvested at different days after planting. The "USDA Color Standards for Frozen French Fried Potatoes" was used for the indexing of chip color (Pedreschi et al., 2012). Values in the photographs indicate corresponding CCI.

fructose), the amino acid lysine, and proteins; as the frying process is extended, the product may be burned (caramelization) resulting in a bitter off flavor (Gould, 1988). Glucose and fructose cause darkening of potato chips, even if present in a very small amount. Hoover and Xander (1961) indicated the discoloration of chips affected most markedly by glucose content $\left(r^{2}= \pm 0.88\right)$ and also by fructose and polyphenol.

\section{Correlations}

Correlation studies revealed significant positive correlations between CCI and 
different chemical parameters [TSS $(\mathrm{r}$ $\left.=0.692^{* *}\right)$, RS $\left(\mathrm{r}=0.822^{* *}\right)$, sucrose $(\mathrm{r}$ $\left.=0.680^{* *}\right)$, and polyphenol content $(\mathrm{r}=$ $\left.0.653^{* *}\right)$ ] of the tested potato varieties (Fig. 4 ) and these co-efficients indicated that these parameters were responsible for the browning and darkening of processed potato products. However, highly significant positive correlation co-efficient $\left(\mathrm{r}=0.822^{* *}\right)$ between $\mathrm{CCI}$ and RS content indicated that RS could be the key sugar responsible for the browning and darkening of the chips and around $82 \%$ variation in chip color could be accounted by $\mathrm{RS}$. The regression equation $\mathrm{CCI}=0.9341 \mathrm{RS}$ - 0.4969 revealed that if RS increases 0.9341 $\mathrm{mg} / \mathrm{g}$ FW then chip color index (CCI) will increase by 1 unit. A good fit $\left(\mathrm{R}^{2}=0.6755\right)$ to the regression equation between $\mathrm{CCI}$ and $\mathrm{RS}$ apparently indicated that RS content was the vital sugar that could be responsible for the discoloration of processed potato products. This result is in agreement with the findings of Roe et al. (1990) and Ezekiel et al. (2003) who also found that the maximum amount of variation in the chip color was accounted by the reducing sugar alone.

\section{Conclusions}

As per the monitoring process, all processing varieties become chemically mature at $80 \mathrm{DAP}$ harvest. Although potato tubers harvested at 80 DAP produce quality and good colored processing products, but lesser DM content may increase the cost of the product. As optimum DM content with moderate level of different sugar contents and acceptable CCI $(<2.00)$ achieved at 90 DAP harvest, therefore, 90 DAP harvest could be mentioned

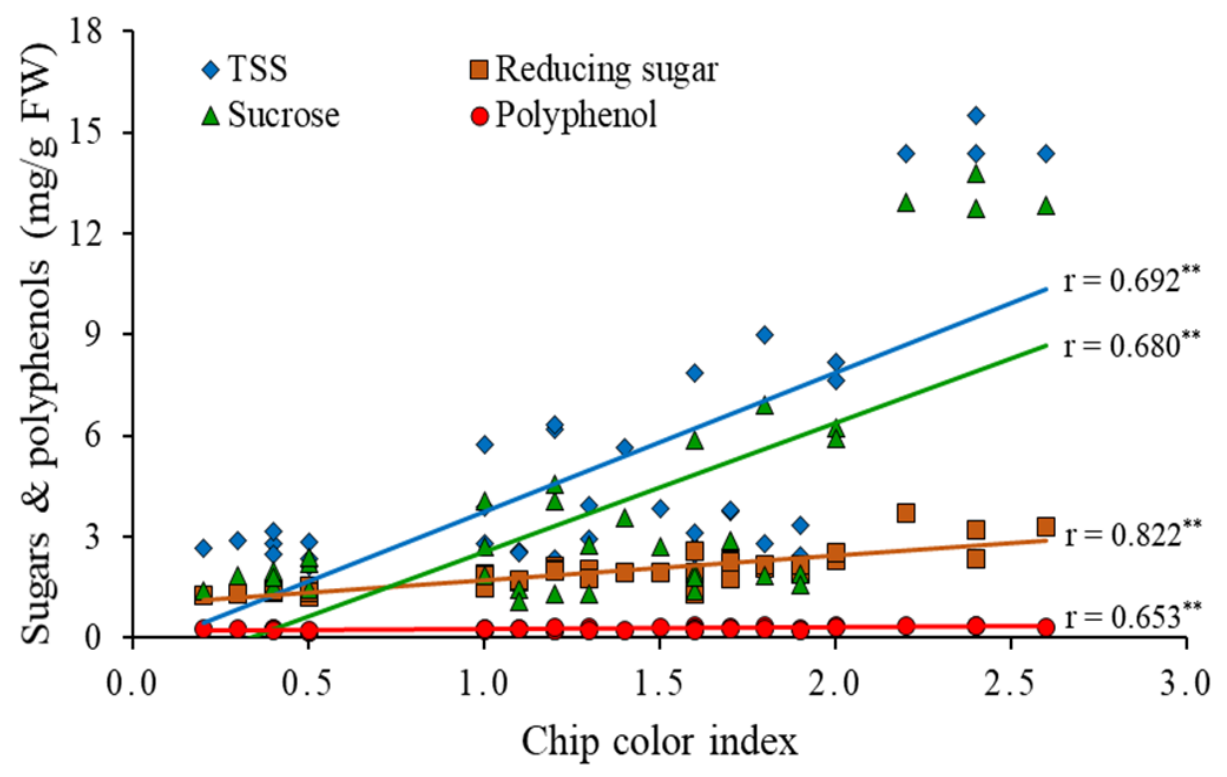

Fig. 4. Relationship of Chip color index (CCI) with total soluble sugar (TSS), sucrose, reducing sugar (RS) and total polyphenol contents of three processing potato varieties. **indicates the correlation coefficient is significant at $p \leq 0.01$. 
as suitable harvest date by compromising some quality parameters (TSS, RS, sucrose, fructose and polyphenol contents). Variety Courage and Lady Rosetta were found more suitable for processing purposes than Asterix. Highly significant and positive correlation $\left(\mathrm{r}=0.822^{* *}\right)$ between CCI and RS and the good fit of the regression line between them indicated that reducing sugar content played the vital role in the browning of the processed potato products.

\section{Acknowledgements}

The authors sincerely acknowledge the Research Management Wing (RMW) of Bangabandhu Sheikh Mujibur Rahman Agricultural University, Bangladesh for the financial support to conduct the research. The authors also acknowledge the contribution of Tuber Crops Research Center (TCRC) of the Bangladesh Agricultural Research Institute (BARI) and Bangladesh Agricultural Development Corporation (BADC) for providing seed tubers for this research.

\section{References}

Adu-Kwarteng, E. E., O. Sakyi-Dawson, G. S. Ayernor, V. Truong, F. F. Shih and K. Daigle. 2014. Variability of sugars in staple-type sweet Potato (Ipomea batatus) cultivars: The effects of harvest time and storage. International Journal of Food Properties. 17: 410-420.

Ainsworth, E. A. and K. M. Gillespie. 2007. Estimation of total phenolic content and other oxidation substrates in plant tissues using folin-ciocalteu reagent. Nature Protocols. 2: 875-877.

Brown, C. R. 2005. Antioxidant in potato. American Journal of Potato Research. 82: 163-72.
Burton, W. G. 1966. The Potato: A Survey of its History and of the Factors Influencing its Yield, Nutritive Value, Quality and Storage. Veenmand and Sonen, Wageningen, The Netherlands.

Burton, W. G. and A. R. Wilson. 1978. The sugar content and sprout growth of tubers of potato cultivar record, grown in different localities, when stored at 10,2 , and $-2^{\circ} \mathrm{C}$. Potato Research. 21: 145-162.

Chen, J. Y., Z. Han, M. Yelian and A. Mitsunaka. 2010. Nondestructive determination of sugar content in potato tubers using visible and near infrared spectroscopy. Japan Journal of Food Engineering. 11: 59 - 64.

Ezekiel, R., B. Singh and D. Kumar. 2003. A reference chart for potato chip colour for use in India. Journal of the Indian Potato Association. 30: 259-265.

Genet, R. A. 1992. Potatoes- the Quest for Processing Quality. New Zealand Institute for Crop \& Food Research Ltd., Private Bag 4704, Christchurch.

Gould. W.A., 1988. Quality of potatoes for chipping manufacture. Pp. 10-20. Supplement to: American Potato Journal vol. 95, The Potato Association of America, Symposium on Potato Quality Industry Needs for Growth. Fort Collins, Colorado, USA.

Hoover, E. F. and P. A. Xander. 1961. Potato composition and chipping quality. American Potato Journal. 38(5): 163-170.

Kadam, S. S., B. N. Wankier and N. R. Adsule. 1991. Potato Production, Processing, and Products. Boca Raton: CRCs Press, USA.

Kang, Y. Y., S. R. Guo, J. Li and J. J. Duan. 2009. Effect of root applied 2-4-epibrassinolide on carbohydrate status and fermentative enzyme activities in cucumber (Cucumis sativus L.) seedlings under hypoxia. Plant Growth Regulator. 57: 259-269. 
Karim, M. R., M. M. Hanafi, S. M. Shahidullah, A. H. M. A. Rahman, A. M. Akanda and A. Khair. 2010. Virus free seed potato production through sprout cutting technique under net-house. African Journal of Biotechnology. 9 (36): 5852-5858.

Kita, A., A. Bąkowska-Barczak, G. Lisińska, K. Hamouz, and K. Kułakowska. 2014. Antioxidant activity and quality of red and purple flesh potato chips. Food Science and Technology. 62(1): 525-531.

Lisinska, G. and W. Leszczynski. 1989. Potato Science and Technology. Elsevier Applied Science, London, UK.

Lulai, E. C. and P. H. Orr. 1979. Influence of potato specific gravity on yield and oil content of chips. American Potato Journal. 56: 379 390.

Marquez, G. and M. C. Anon. 1986. Influence of reducing sugars and amino acids in the color development of fried potatoes. Journal of Food Science. 51: 157-160.

Marwaha, R. S. 1998. Factors determining processing quality and optimum processing maturity of potato cultivars grown under short days. Journal of Indian Potato Association. 25: 95-102.

Mathur, A. 2003. Studies on phosphorylation status of starch in potato tubers (Solanum tuberosum L.). MSc. Thesis, Department of Biotechnology and Environmental Sciences. Thapar Institute of Engineering and Technology, Patiala, India. Pp. 10-14.

Mazza, G. 1983. Processing/Nutritional quality changes in potato tubers during growth and long term storage. Canadian Institute of Food Science and Technology Journal. 16 (1): 39- 44.

Miller, G. L. 1959. Use of dinitrosalicylic acid reagent for determination of reducing sugar. Annals of Chemistry. 31 (3): 426-428.
Mottram, D. S., B. L. Wedzicha and A. T. Dodson. 2002. Acrylamide is formed in the Maillard reaction. Nature. 419: 448-449.

Nayak, B., J. D. J. Berrios, J. R. Powers, J. Tang and Y. Ji. 2011. Colored potatoes (Solanum tuberosum L.) dried for antioxidantrich value-added food. Journal of Food Processing and Preservation. 35: 571-580.

Pandey, S. K., S. M. P. Khurana, S. V. Singh, D. Kumar and P. Kumar. 2005. Evaluation of Indian and exotic potato varieties for sustaining processing industries in North Western plains of India. Indian Journal of Horticulture. 62:155-159.

Pavlista, A. D. and J. C. Ojala. 1997. Potatoes: Chips and French Fry Processing. Pp. 284-287. In: O. Smith et al. (ed.) Processing VegetablesScience and Technology. Technomac Publishing Co., Lancaster. USA.

Pedreschi, F., A Bunger, O. Skurtys, P. Allen and X. Rojas. 2012. Grading of potato chips according to their sensory quality determined by color. Food Bioprocess Technology. 5: 2401-2408.

Pedreschi, F., P. C. Moyano, K. Kaack, and K. Granby. 2005. Color changes and acrylamide formation in fried potato slices. Food Research International. 38: 1-9.

Pressey, R. 1969. Role of invertase in the accumulation of sugars in cold stored potatoes. American Potato Journal. 14: 269- 290.

Preston, A. D. 2003. Maintinance of Potato Processing: Chemical Maturity Monitoring. Presented at the Idaho Potato Conference on January. 22, 2003.

Roe, M. A., R. M. Faulks and J. L. Belsten. 1990. Role of reducing sugars and amino acids in fry colour of chips from potatoes grown under different nitrogen regimes. Journal of the Science of Food and Agriculture. 52: 207-214. 
Rommens, C. M., R. Shakira, M. Heap and K. Fessenden. 2010. Tastier and healthier alternatives to French fries. Journal of Food Science. 75: 109-115.

Shallenberger, R. S., O. Smith and R. H. Treadway. 1959. Food Color Changes: Role of the sugar in the browning reaction in potato chips. Journal of Agricultural Food Chemistry. 7: 274- 277.

Sharkar, M., J. U. Ahmed, S. F. Ahmed, S. M. Z. AlMeraj and M. Mohi-Ud-Din. 2019. Effect of harvesting dates on the yield and tuber quality of processing potatoes. Bangladesh Journal of Agricultural Research. 44(1): 179-193.

Singleton, V. L., R. Orthofer and R. M. LamuelaRaventos. 1999. Analysis of total phenols and other oxidation substrates and antioxidants by means of Folin-Ciocalteu reagent. Methods in Enzymology. 299: 152-178.

Söğüt, T. and F. Öztürk. 2011. Effects of harvesting time on some yield and quality traits of different maturing potato cultivars. African Journal of Biotechnology. 10(38): 73497355.

Sowokinos, J. R. and D. A. Preston. 1988. Maintenance of Potato Processing Quality by Chemical Maturity Monitoring. Station Bulletin 586-1988 (Item no. Ad-SB-3441) Minnesota Agricultural Experiment Station.

Van Es, A. and A. J. Hartmans. 1987. Starch and sugars during tuberization, storage and sprouting in storage of potatoes. Pp. 79113. In A. Rastovski et al. (Ed.) Storage of Potatoes: Post-harvest Behavior, Store Design, Storage Practice, Handling. Pudoc, Wageningen. The Netherlands.

Wang-Pruski, G. and J. Nowak. 2004. Potato after cooking darkening. American Journal of Potato Research. 81: 7-16.

Xue, L. 1985. A Handbook of Experiments for Plant Physiology. Shanghai Science and Technology, Shanghai, China. 
